\title{
Carcinoma Primario del Ovario
}

\author{
Análisis de 349 casos \\ Stanley W. Kent, Donald G. McKay \\ American Journal of Obstetrics and Gynecology. Vol. 80 No 3 Sept. 1960
}

Consiste el trabajo en la revisión de los carcinomas de ovario vistos en el "Free Hospital for women" de Brookliñe, Mass, E. U. A., de $190 \div$ a 1952 Un $93 \%$ de las pacientes fueron controladas por un mínimum de 5 años. El criterio de gradación histológica fue el mismo usado por Allan y Hertig. La clasificación clínica fue la descrita por Munnell y Taylor y posteriormente por Helsel. El tumor ovárico más frecuentemente encontrado fue el fibroma del ovario con 740 casos. Entre los malignos el cistadenocarcinoma seroso con 214 casos y el Tumor de Células de la granulosa con 15 casos fueron los de más frecuente ocurrencia.

Los síntomas más frecuentes fueron los ya conocidos de dolor y aumento de volumen abdominal junto con hemorragia genital. Los tumores de mayor malignidad de acuerdo con la clasificación histológica fueron los no diferenciados que en un $76.7 \%$ fueron clasificados como grado III. Lo mismo puede decirse en cuanto a estado clínico. Los tumores clasificados como grado I dieron una supervivencia a los cinco años del $65 \%$ en contraste con $10.4 \%$ para los grados III.

El estado clínico I dio una supervivencia del 53\% en contraste con el $10 \%$ para el estado IV. Los estados III dieron una supervivencia del $40 \%$ a los cinco años y esto se considera como causado por la irradiación postoperatoria.

La diferencia porcentual entre los casos tratados con rayos $\mathrm{X}$ y aquellos que no recibieron roentgenoterapia puede apreciarse en las cifras de supervivencia de 5 años, de $45.5 \%$ y $32.9 \%$ respectivamente. 
La rata absoluta de supervivencia de 5 años para todas las 349 pacientes fue de $36.4 \%$.

J. V. M.

(1) ALlAN Y HeRTIG. Am. J. Obs. \& Gynec. 58: 640, 1949.

CIRUGIA DURANTE EL EMBARAZO

Conrado Zuckermann

Revista Mexicana de Cirugía, Ginecología y Cáncer

Año XXVIII № 5 Mayo 1960

Se refiere este artículo únicamente a la cirugía no directamente relacionada con el embarazo. Se presentan tres estadísticas de cirugía durante la gestación. Sobre un total de 1999 intervenciones practicadas en tres diferentes servicios Obstétrico-Ginecológicos en un período de cuatro años se intervinieron 44 pacientes. La mayor parte de ellas fueron debidas a apendicitis agudas, carcinoma de cuello y carcinoma del seno.

El autor preconiza la anestesia raquídea y aconseja no operar en miomas uterinos excepto cuando estén produciendo una severa sintomatología. Anota que la miomectomía en úteros gestantes se acompaña del aborto en el $25 \%$ de los casos.

El artículo lo complementa un total de 168 citas bibliográticas.

J. V.M. 